\title{
Highly effective three-dimensional functionalization of graphite to graphene by wet chemical exfoliation methods
}

\author{
Piotr Kamedulski ${ }^{1}$ D $\cdot$ Anna Ilnicka ${ }^{1} \cdot$ Jerzy P. Lukaszewicz ${ }^{1,2} \cdot$ Malgorzata Skorupska $^{1}$
}

Received: 6 December 2018 / Revised: 18 March 2019 / Accepted: 19 March 2019 / Published online: 26 March 2019

(c) The Author(s) 2019

\begin{abstract}
The paper presents results on the three-dimensional (3D) functionalization of graphite-originated flakes to graphene by carbonization of specific precursors in the presence of a hard template. In situ precipitated $\mathrm{Na}_{2} \mathrm{CO}_{3}$ nanocrystals or $\mathrm{CaCO}_{3}$ nano-powder were used as a hard template. Graphene flakes were obtained by a wet chemistry exfoliation of commercial graphite. The flakes were premixed with a non-specific binder and the hard template and then carbonized at temperatures of 700 to $800{ }^{\circ} \mathrm{C}$ under the flow of nitrogen. The addition of a template allowed to increase the surface area up $287 \mathrm{~m}^{2} / \mathrm{g}$ for the $\mathrm{Na}_{2} \mathrm{CO}_{3}$ template and $333 \mathrm{~m}^{2} / \mathrm{g}$ in the case of $\mathrm{CaCO}_{3}$, while the surface area of $25 \mathrm{~m}^{2} / \mathrm{g}$ was noted for the raw graphite. Several instrumental methods were applied for the characterization of the obtained 3D-graphene materials: combustion elemental analysis, SEM, HRTEM, XPS, Raman spectroscopy and low-temperature adsorption of nitrogen. The effect of the addition of a template and the carbonization temperature on the surface area of the 3D structured graphene was demonstrated. The wet-chemistry method led to an efficient deglomeration of graphene flakes to double (DLG) and few (FLG) layered graphene. The proposed method is inexpensive.
\end{abstract}

Keywords 3D graphene $\cdot$ Wet chemical exfoliation $\cdot$ Surface area $\cdot$ Porous structure $\cdot$ Hard template method

\section{Introduction}

The discovery of graphene in 2004 by a group of researchers led by Novoselov et al. (2004) caused a rapid increase in interest in this material, mainly due to its unique properties (Eftekhari and Garcia 2017; Smędowski and Muzyka 2013; Hancock 2011; Katsnelson 2007). Commonly, graphene is regarded as a two-dimensional (2D) structure, difficult to obtain in its pristine form and characterized by a high production cost. Plenty of potential applications rely on the outstanding properties of graphene-like durability (Tian et al. 2014), high thermal and electrical conductivity, etc. (Yung et al. 2013). Despite a tremendous progress in recent years, the problem of inexpensive industrial fabrication of graphene-based materials is intensively investigated around the world. Beside the suggested graphene application in

Piotr Kamedulski

pkamedulski@umk.pl

1 Faculty of Chemistry, Nicolaus Copernicus University, Gagarina 7, 87-100 Torun, Poland

2 Centre for Modern Interdisciplinary Technologies, Wilenska 4, 87-100 Torun, Poland electronic devices, there is a demand for three-dimensional (3D) structures consisting of graphene building stones like small graphene flakes occasionally supplemented with heteroatoms like the so-called functional groups (oxygen, nitrogen-containing) of specific chemical properties.

Nowadays, a different precursor can be applied for the manufacturing of graphene flakes: graphite, highly oriented pyrolytic graphite, saturated and unsaturated hydrocarbons, aromatic hydrocarbons, etc. (Smędowski and Muzyka 2013; Torbicz and Pijanowska 2012). Generally, graphene production (including graphene flakes) methods can be divided into two main classes, i.e., bottom-up method and top-down method (Kim et al. 2010). The bottom-up method depends on the chemical reaction of molecular building blocks to form covalently linked 2D networks. The top-down method is based on the exfoliation of graphite, which directly delivers graphene flakes. Several reviews have already summarized the up-to-date progress of various graphene production methods, such as mechanical exfoliation, chemical synthesis, liquid-phase exfoliation, thermal chemical vapor deposition (CVD) and microwave synthesis (Kamedulski et al. 2018c; Yuan et al. 2016; Zhong et al. 2015; Yi and Shen 2015; Cui et al. 2011). A very important consideration for any material 
to be produced on an industrial scale is the cost-effectiveness and quality of the product. The method of non-oxidative liquid-phase exfoliation seems to be more favorable in comparison to other methods regarding the graphene quality, cost of production and the upscaling to industrial scale. In most known approaches of that type, graphite powder is dispersed in specific organic solvents, such as $\mathrm{N}, \mathrm{N}$-dimethylformamide (DMF), $\gamma$-butyrolactone (GBL), 1,3-dimethyl-2-imidazolidinone (DMEU) and $N$-methylpyrrolidone (NMP). Solvent dispersion is often supported by sonication and centrifugation (Hernandez et al. 2008; Ravikumar and Gopukumar 2013).

The current work is aimed at the elaboration of new synthesis pathways of porous 3D graphene being, in fact, a complex structure built of glued graphene flakes. New knowledge on the principles of 3D structuring of graphene will open up new practical applications for such materials as adsorbents, catalysts and electrode material in electric power devices like fuel cells (Mao et al. 2015; Zhu et al. 2018), supercapacitors ( $\mathrm{Li}$ et al. 2015, 2018; Wang and Xu 2016; Ping et al. 2017), Li-ion batteries (Cai et al. 2017; Cheng et al. 2017) and photovoltaic cells (Ma and Chen 2015; Han et al. 2014; Zhang et al. 2013; Fan et al. 2012; Yu et al. 2015). Moreover, porous 3D graphene may improve the performance of solar cells (Acika and Darling 2016; Zhang et al. 2015; Roy-Mayhew and Aksay 2014; Lim et al. 2017).

Hard templating is an effective strategy to produce porous materials from non-porous raw materials, which do not yield porous carbon matrixes after carbonization of the materials. For example, a hierarchical microporous-mesoporous carbon with a large surface area and pore volume was prepared by the simple one-step carbonization of a mixture of magnesium gluconate and phenolic resin (Niu et al. 2017). Templating means that a powdered template must be added to a precursor, which is going to be turned into a porous carbon matrix. Upon heat-treatment, the main organic precursor is converted into a carbon phase in which template particles remain. After the removal of hard template particles, the pores are left behind. The hard template method has been successfully applied for manufacturing of highly porous $\mathrm{N}$-rich carbon matrixes from chitin, chitosan, microorganisms and selected amino acids (Ilnicka et al. 2017b; Ilnicka and Lukaszewicz 2015; Kucinska et al. 2012; Leżańska et al. 2014). A wide review of such materials, their modifications and potential electrochemical applications was conducted by Ilnicka et al. (Ilnicka and Lukaszewicz 2018).

Some preliminary works (Ilnicka and Lukaszewicz 2016; Kamedulski et al. 2018a; Ilnicka et al. 2017a) and patent application (Kamedulski et al. 2018b) allowed to assume that deglomerated graphene flakes (non-oxidative approach) may be efficiently and durably 3D structured by means of two different templates, i.e., $\mathrm{Na}_{2} \mathrm{CO}_{3}$ and $\mathrm{CaCO}_{3}$. This work is based on an assumption and additionally proposes to use an additional reagent (cationic surfactant) to simplify the process of graphene exfoliation form commercial graphite grains. The effects of mass ratio, cationic surfactant and carbonization temperature on the properties of 3D graphene structures are explored in this work.

\section{Experimental}

\subsection{Synthesis of 3D graphene}

Commercial graphite (SkySpring Nanomaterials, Inc.) with high purity ( $99.5 \mathrm{wt} . \%$ ) was modified to three-dimensional graphene by means of two procedures. In the first method, $1 \mathrm{~g}$ of commercial graphite was added to $3 \mathrm{~g}$ of $\mathrm{CaCO}_{3}$ (purchased from SkySpring Nanomaterials, INC., average particle size of $15-40 \mathrm{~nm}$ ), and mixed mechanically. Then, $50 \mathrm{ml}$ of 1-methyl-2-pyrrolioline (Sigma-Aldrich) was added and mixed well. Next, the mixture was stored at room temperature for $24 \mathrm{~h}$. After this time, the flask was placed for $1 \mathrm{~h}$ in an ultrasonic bath (room temperature) and washed with distilled water using a Büchner funnel. Then, it was dried in an electric furnace at $100{ }^{\circ} \mathrm{C}$ for $24 \mathrm{~h}$. After drying, $15 \mathrm{ml}$ of furfuryl alcohol (POCh) was added, mixed with 3 drops of concentrated phosphoric acid aqueous solutions $(75 \%)$ to each sample and mixed well, followed by heating of the material at $80{ }^{\circ} \mathrm{C}$ in an oven for $24 \mathrm{~h}$ to allow the polymerization of furfuryl alcohol, and subsequently carbonization at temperatures of 700 to $800{ }^{\circ} \mathrm{C}$ for $1 \mathrm{~h}$. The mass was heated under the flow of nitrogen at a rate of $10^{\circ} \mathrm{C} / \mathrm{min}$ in a tube furnace (Thermolyne F21100). After this process, the prepared samples remained in a tube furnace under the flow of nitrogen in order to reached room temperature. After carbonization, the samples were treated with concentrated (34-37\%) $\mathrm{HCl}$ for $20 \mathrm{~min}$ ( $1 \mathrm{~g}$ of carbon was used per $12 \mathrm{ml}$ of $\mathrm{HCl}$ ) and then washed with distilled water using a Büchner funnel, until the $\mathrm{pH}$ of the solution reached 6-7. Then, it was dried in an electric furnace at $100{ }^{\circ} \mathrm{C}$ for $24 \mathrm{~h}$. The action of $\mathrm{HCl}$ opened pores in the carbon matrix by etching the template. The procedure was found to be the most effective regarding the removal of $\mathrm{CaCO}_{3}$ or $\mathrm{Na}_{2} \mathrm{CO}_{3}$. An analogous procedure was performed in the second method where $\mathrm{Na}_{2} \mathrm{CO}_{3}(\mathrm{POCh})$ was used as a template. In the second method, the aqueous solution of $\mathrm{Na}_{2} \mathrm{CO}_{3}(16.9 \%)$ was supplemented with $2 \mathrm{~g}$ of commercial graphite, and then mixed well for $1.5 \mathrm{~h}$ in a magnetic stirrer at room temperature. Next, $20 \mathrm{ml}$ of 1-methyl-2-pyrrolioline was added, mixed with $0.1 \mathrm{ml}$ of cetyltrimethylammonium chloride solution (CTAC) $25 \mathrm{wt} . \%$ in $\mathrm{H}_{2} \mathrm{O}$, and then mixed well for $1.5 \mathrm{~h}$ in a magnetic stirrer. After this time, the flask was placed for $1 \mathrm{~h}$ in an ultrasonic bath (at room temperature, $40 \mathrm{~Hz}$ frequency, $100 \mathrm{~W}$ power), washed with distilled water using a Büchner funnel. Then, it was dried in an electric furnace at $100{ }^{\circ} \mathrm{C}$ for 
$24 \mathrm{~h}$. After drying, every $2 \mathrm{~g}$ of powder was supplemented with $15 \mathrm{ml}$ of furfuryl alcohol, mixed well with 3-5 drops of concentrated phosphoric acid aqueous solutions (75\%). The three-dimensional graphene obtained in these methods was denoted as GF_Na_1:1_T, GF_Ca_1:1_T, GF_Na_1:3_T and GF_Ca_1:3_T where: e.g. GF_Na_1:1-means the mass ratio of graphite $(1 \mathrm{~g})$ to $\mathrm{Na}_{2} \mathrm{CO}_{3}(1 \mathrm{~g})$, GF_Ca_1:3means the mass ratio of graphite $(1 \mathrm{~g})$ to $\mathrm{CaCO}_{3}(3 \mathrm{~g}), \mathrm{T}$-is the carbonization temperature $\left({ }^{\circ} \mathrm{C}\right)$. The sample denoted as GF_0 means pure graphite used in the research. The only losses were the amounts which were retained on the wall of laboratory vessels. To minimize graphite/graphene losses, all laboratory vessels were rinsed with distilled water and the residues of synthetic material were added to its main portion. Therefore, the weight losses were lower than $5 \%$ and the yield can be estimated as about $95 \%$ in relation to graphite.

\subsection{Materials characterization}

The graphene samples were examined by the low-temperature adsorption of nitrogen method. The relevant isotherms of all the samples were measured at $-196^{\circ} \mathrm{C}$ using an automatic adsorption instrument ASAP 2010 (Micromeritics, USA). Prior to gas adsorption measurements, the carbon materials were outgassed under a vacuum at $200{ }^{\circ} \mathrm{C}$ for $2 \mathrm{~h}$. The specific surface area $\left(\mathrm{S}_{\mathrm{BET}}\right)$ was determined based on the Brunauer-Emmett-Teller (BET) method from nitrogen adsorption data in the relative pressure range of 0.02 to 0.2 . The micropore volume $\left(\mathrm{V}_{\mathrm{mi}}\right)$ was calculated by using the $\mathrm{t}$-plot method. The total pole volume $\left(\mathrm{V}_{\mathrm{t}}\right)$ was determined from the amount of gas adsorbed at the relative pressure of 0.99 .

The volumetric elemental composition (carbon, nitrogen and hydrogen) of the materials was analyzed by means of a combustion elemental analyzer (Vario MACRO CHN, Elementar Analysensysteme GmbH).

The morphology of the carbons prepared from graphite was analyzed by scanning electron microscopy (SEM, 1430 VP, LEO Electron Microscopy Ltd.). The obtained carbons were also examined by high-resolution transmission electron microscopy (HRTEM, FEI Europe production, model Tecnai F20 X-Twin). The carbon materials obtained prior to the HRTEM microscopic analysis were dispersed in ethanol and treated with an Inter Sonic IS-1K bath for $15 \mathrm{~min}$ and deposit on holey carbon-coated copper grids.

X-ray photoelectron spectroscopy (XPS) measurements were performed using a VG Scientific photoelectron spectrometer ESCALAB-210 with the use of Al K $\alpha$ radiation $(1486.6 \mathrm{eV})$ from an X-ray source operating at $14.5 \mathrm{kV}$ and $25 \mathrm{~mA}$. Survey spectra were recorded for all the samples in the energy range from 0 to $1350 \mathrm{eV}$ with $0.4 \mathrm{eV}$ step. Highresolution spectra were recorded with $0.1 \mathrm{eV}$ step, $100 \mathrm{~ms}$ dwell time and $25 \mathrm{eV}$ pass energy. A 90-degree take-off angle was used in all measurements. The curve fitting was performed using the AVANTAGE software provided by Thermo Electron, which describes each component of the complex envelope as a Gaussian-Lorentzian sum function; a constant $0.3( \pm 0.05) \mathrm{G} / \mathrm{l}$ ratio was used. The background was fitted using the nonlinear Shirley model. Scofield sensitivity factors and the measured transmission function were used for quantification.

The graphene samples were examined by Raman spectroscopy (microscop Renishaw InVia, Renishaw plc (Gloucestershire, UK), Laser: Modu-Laser Stellar-REN, Multi-Line (max. Power $150 \mathrm{~mW}$ ), Leica DM1300M camera Infinity 1; objective: Leica, N PLAN L50x/0.5). All of the spectra were collected at ambient temperature.

\section{Results and discussion}

\subsection{Structural characterization and elemental composition}

The elemental composition and surface parameters for the obtained samples of porous $3 \mathrm{D}$ graphene are given in Table 1. The elemental analysis revealed that the content of carbon increases with increasing carbonization temperature
Table 1 Elemental composition and porosity parameters obtained from $\mathrm{N}_{2}$ sorption analysis of 3D graphene

\begin{tabular}{|c|c|c|c|c|c|c|}
\hline \multirow[t]{2}{*}{ Sample } & \multicolumn{3}{|c|}{ Elemental analysis (wt.\%) } & \multirow[t]{2}{*}{$\mathrm{S}_{\mathrm{BET}}\left(\mathrm{m}^{2} / \mathrm{g}\right)$} & \multirow[t]{2}{*}{$\mathrm{V}_{\mathrm{mi}}\left(\mathrm{cm}^{3} / \mathrm{g}\right)$} & \multirow[t]{2}{*}{$\mathrm{V}_{\mathrm{t}}\left(\mathrm{cm}^{3} / \mathrm{g}\right)$} \\
\hline & $\mathrm{C}$ & $\mathrm{N}$ & $\mathrm{H}$ & & & \\
\hline Commercial graphite & 91.0 & 0.5 & 0.8 & 25 & 0.001 & 0.055 \\
\hline GF_Na_1:1_700 & 90.9 & 0.3 & 1.3 & 200 & 0.070 & 0.102 \\
\hline GF_Na_1:1_800 & 91.1 & 0.4 & 0.9 & 118 & 0.037 & 0.060 \\
\hline GF_Na_1:3_700 & 93.2 & 0.1 & 1.1 & 287 & 0.080 & 0.154 \\
\hline GF_Na_1:3_800 & 94.2 & 0.4 & 0.8 & 267 & 0.071 & 0.136 \\
\hline GF_Ca_1:1_700 & 94.2 & 0.3 & 0.7 & 333 & 0.092 & 0.199 \\
\hline GF_Ca_1:1_800 & 93.0 & 0.2 & 0.6 & 200 & 0.044 & 0.134 \\
\hline GF_Ca_1:3_700 & 94.0 & 0.2 & 0.7 & 169 & 0.032 & 0.213 \\
\hline GF_Ca_1:3_800 & 91.8 & 0.4 & 0.9 & 255 & 0.053 & 0.343 \\
\hline
\end{tabular}


in the case of $\mathrm{Na}_{2} \mathrm{CO}_{3}$. Generally, the carbon content in all investigated series of 3D graphene is very high (higher than $90 \mathrm{wt}$ \%). The $\mathrm{N}_{2}$ sorption analysis for raw commercial graphite materials indicated a specific surface area of $25 \mathrm{~m}^{2} / \mathrm{g}$, which, in fact, is too low for plenty of potential applications like electrode manufacturing. The results obtained in the case of the wet chemical exfoliation method combined with the hard template method (two templates: $\mathrm{Na}_{2} \mathrm{CO}_{3}$ ) indicated that the increase of the template ratio to graphite from 1:1 to $1: 3$ causes an increase of the specific surface area up $287 \mathrm{~m}^{2} / \mathrm{g}$ for both carbonization temperatures $\left(700{ }^{\circ} \mathrm{C}\right.$ and $\left.800{ }^{\circ} \mathrm{C}\right)$. In the case of $\mathrm{CaCO}_{3}$, a more intensive admission of the template resulted in a reversed effect. Nevertheless, the application of $\mathrm{CaCO}_{3}$ allowed to achieve the ever-highest surface area of $333 \mathrm{~m}^{2} / \mathrm{g}$. Generally, for both templates, an increase of the carbonization temperature from 700 to $800{ }^{\circ} \mathrm{C}$ causes a decrease of the surface area except for the sample GF_Ca_1:3_800. The templates differ regarding their form when admitted to the reaction mixture. $\mathrm{Na}_{2} \mathrm{CO}_{3}$ is added as a saturated water solution. $\mathrm{Na}_{2} \mathrm{CO}_{3}$ nanocrystals precipitate among exfoliated graphene flakes upon drying of the reaction mixture. On the contrary, $\mathrm{CaCO}_{3}$ is added already as a nano-powder of a specific grain diameter, i.e., $15-40 \mathrm{~nm}$, according to the product specification. Thus, differences in pore size distribution were expected.

The micropore volume calculated for series GF_ Na_1:1_T and GF_Na_1:3_T proved that their contribution to the total pore volume was very high and placed in the range of 52-68\%. The cationic surfactant (CTAC), which was used for GF_Na_1:1_T and GF_Na_1:3_T, allowed to obtain improved porosity in comparison to the application of sodium laureth ether sulphate (SLES) as described in other works (Ilnicka et al. 2017a). The application of $\mathrm{Na}_{2} \mathrm{CO}_{3}$ prefers the formation of micropores. In turn, the application of $\mathrm{CaCO}_{3}$ nano-powder as a template led to the domination of mesopores. In this case, the share of $\mathrm{V}_{\mathrm{mi}}$ did not exceed $46 \%$ of the total pore volume (Table 1). Nevertheless, the template method allowed to obtain durable 3D graphene structures of a diversified porosity, microporous or mesoporous for $\mathrm{Na}_{2} \mathrm{CO}_{3}$ and $\mathrm{CaCO}_{3}$ template, respectively.

In general, nitrogen can positively influence on electric conductivity of graphene. Table 1 proves that the starting material, i.e., commercial graphite is itself the source of nitrogen. The nitrogen content was of $0.5 \mathrm{wt} . \%$ but it got reduced after 3D structuration. Thus, electrical conductivity of 3D structured graphene should be less affected by nitrogen then commercial graphite. It is not a positive side effect of 3D structuring procedure.

The results of combustion elemental analysis allowed to determine the overall bulk content of three principal elements: $\mathrm{C}, \mathrm{N}$ and $\mathrm{H}$, while the specific chemical environment of these elements and oxygen remains unknown. Therefore, $3 \mathrm{D}$ porous graphene samples were examined by XPS. The
XPS spectra of the representative GF_Na_1:3_T series were determined and are depicted in Fig. 1. Additional detailed data of the spectroscopic analysis are given in Table 2. It is visible that all analyzed samples possess a very high content of carbon 97 at.\%. As shown in Fig. 1, the deconvolution of $\mathrm{C} 1 \mathrm{~s}$ spectra prove that surface $\mathrm{C}$ atoms are occasionally bonded to $\mathrm{O}$, which is confirmed by five major peaks at 284.8, 285.81, 287.61, 289.43, 291.22, 292.95 and $294.4 \mathrm{eV}$ assigned to $\mathrm{sp}^{2} \mathrm{C}(\mathrm{C}-1), \mathrm{sp}^{3} \mathrm{C}(\mathrm{C}-2), \mathrm{C}-\mathrm{O}(\mathrm{C}-3), \mathrm{C}=\mathrm{O}(\mathrm{C}-4)$, and $\mathrm{O}=\mathrm{C}-\mathrm{O}(\mathrm{C}-5)$, respectively. Nevertheless, the overall oxygen content is very low when compared to typical pyrolytic carbons or graphene oxide and reduced graphene oxide (Yang et al. 2018; Pei and Cheng 2012). Therefore, the performed synthesis of 3D structured graphene is definitely a non-oxidative method. The total amount of oxygen in samples GF_Na_1:3_700, and GF_Na_1:3_800 is 2.67, and 2.86 at. \%, respectively. It can be noted that the oxygen content increased slightly with the carbonization temperature. Figure 1 shows the nature of $\mathrm{O}$ bonding on the carbon surface, where O-1 and O-2 are the major peaks on those spectra. A binding energy of $531.72 \mathrm{eV}(\mathrm{O}-1)$ and $533.48 \mathrm{eV}$ (O-2) for these peaks are assigned for molecular oxygen and $\mathrm{C}-\mathrm{O}$ bonds, respectively.

The morphology of 3D graphene samples was characterized by SEM and HRTEM (Fig. 2). The SEM and HRTEM images were recorded for GF_Na_1:1_700, GF Ca_1:1_700, GF_Na_1:3_700 and GF_Ca_1:3_800 samples. Figure 2a, b containing images of GF_Na_1:1_700 and GF_Ca_1:1_700 samples, do not reveal major differences as the overall morphology and the level of graphene deglomeration despite different graphene to template ratio. All investigated samples had similar irregular surface characteristics due to the presence of randomly oriented graphene layers. The SEM images do not allow to determine the degree of graphene deglomeration in the examined 3D structures. The HRTEM method allowed for a better insight into the deglomeration process. The high resolution allowed to observe thinny graphene flakes exfoliated previously from graphite grains. The thinny flakes are the building stones of 3D structures under examination. Additionally, it can be concluded that the analyzed materials are pure without a residue of the template. The degree of deglomeration can be defined as DLG (Double Layered Graphene) and FLG (Few Layered Graphene) by using the HRTEM method (Fig. 2c, d).

\subsection{Raman spectroscopy results}

To confirm the quality of the investigated materials, the 3D graphene samples were analyzed by Raman spectroscopy. Figure 3 shows the Raman spectra recorded for $532 \mathrm{~nm}$ for GF_Na_1:3_T and GF_Ca_1:1_T series. The most characteristic graphene/graphite bands occur in 

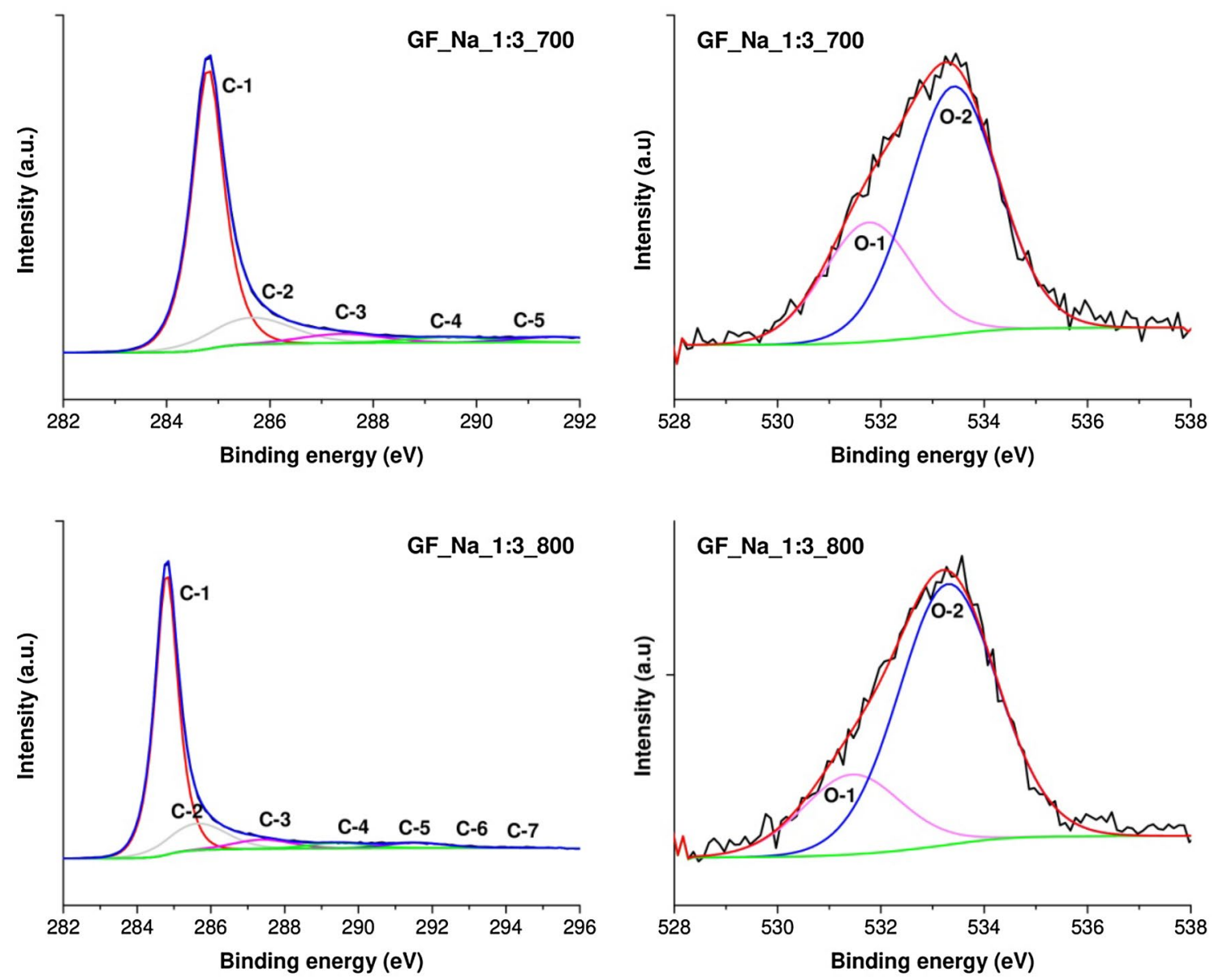

Fig. 1 Deconvolution of high resolution XPS spectra of carbon and oxygen elements in a 3D graphene sample of C 1s and O 1s spectra for GF_Na_1:3_700 and GF_Na_1:3_800 sample

Table 2 Elemental composition of synthesized GF_Na_1:3_T samples obtained from XPS spectra

\begin{tabular}{llll}
\hline Peak & \multicolumn{2}{l}{ Binding content (at.\%) } \\
\cline { 2 - 4 } & Energy (eV) & GF_Na_1:3_700 & GF_Na_1:3_800 \\
\hline C 1s (C-1) & 284.80 & 70.29 & 66.86 \\
C 1s (C-2) & 285.81 & 15.41 & 15.56 \\
C 1s (C-3) & 287.61 & 5.26 & 6.17 \\
C 1s (C-4) & 289.43 & 3.11 & 3.26 \\
C 1s (C-5) & 291.22 & 3.03 & 2.53 \\
C 1s (C-6) & 292.95 & - & 1.93 \\
C 1s (C-7) & 294.40 & - & 0.64 \\
& $\%$ of total & 97.10 & 96.95 \\
O 1s (O-1) & 531.72 & 0.87 & 0.67 \\
O 1s (O-2) & 533.48 & 1.80 & 2.19 \\
O 1s (O-3) & 536.51 & - & - \\
& \% of total & 2.67 & 2.86 \\
Residual ele- & \% of total & 0.23 & 0.19 \\
ments (Na, Cl, & & & \\
N, P) & & & \\
\hline
\end{tabular}

the spectral region 500 and $3500 \mathrm{~cm}^{-1}$ (Grodecki 2013; Choi et al. 2014). Figure 3 shows example Raman spectra containing three main bands at $1348 \mathrm{~cm}^{-1}$ (D-band), $1578 \mathrm{~cm}^{-1}$ (G-band), and $2712 \mathrm{~cm}^{-1}$ (G'-band). The $\mathrm{D}$-band intensity is attributed by some authors to the presence of SLG/DLG sheets (Drewniak et al. 2014; Gayathri et al. 2014). The placement of the $G$ ' band is related to the deglomaration degree of graphene layers. Intense deglomation towards double layered graphene (DLG) results in the shift of the peak G' towards $2700 \mathrm{~cm}^{-1}$, of which effect is observable in the presented spectra, too. The significant intensity of peak D is usually interpreted as a result of an intense deglomeration of graphene towards SLG/DLG and FLG. As for graphite, the intensity of D-band is relatively low. G-band in graphite is located close to $1560 \mathrm{~cm}^{-1}$, while the band for investigated samples is located close to $1580 \mathrm{~cm}^{-1}$, which is a value typical for graphene. The intensity ratio $\mathrm{I}_{2 \mathrm{D}} / \mathrm{I}_{\mathrm{G}}$ and $\mathrm{I}_{\mathrm{D}} / \mathrm{I}_{\mathrm{G}}$ of investigated samples indicate that the obtained samples consisting multilayer nature of the graphene. 
Fig. 2 SEM images of $\mathbf{a}$ GF_Na_1:1_700, b GF_ Ca_1:1_700, and HRTEM images of $\mathbf{c}$ GF_Na_1:3_700 and d GF_Ca_1:3_800 samples (arrows on the images $(\mathbf{c})$ and (d) showing of thin DLG/FLG sheets)
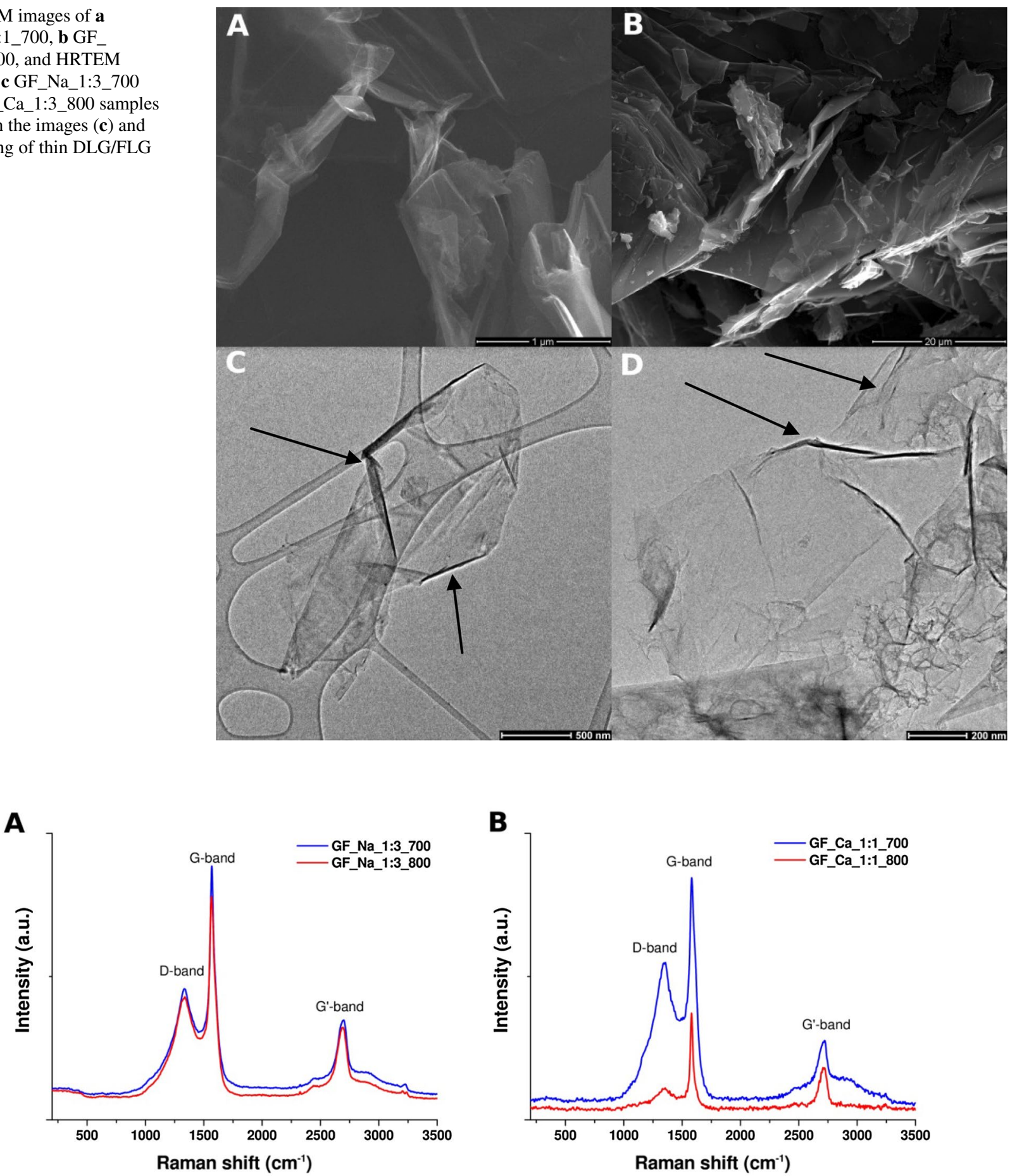

Fig. 3 Raman spectra of a GF_Na_1:3_T and $\mathbf{b}$ GF_Ca_1:1_T samples

In summary, the presented results of HRTEM images, and Raman spectra clearly indicate that the presented synthesis pathway led to 3D graphene samples consisting of durably fixed DLG and/or FLG/MLG sheets.

\section{Conclusion}

This paper presents regular studies on the preparation of $3 \mathrm{D}$ porous graphene by the wet chemical exfoliation method using a low-cost graphite as a precursor. This 
proposed synthesis is important from a practical point of view because it is based on an inexpensive raw material, such as commercial graphite. A high effectiveness was achieved since commercial graphite being a non-porous solid of very low surface area usually below $10 \mathrm{~m}^{2} / \mathrm{g}$ got converted into a micro-mesoporous solid of high surface area. The joint application of a cationic surfactant (CTAC), sonication, hard templates $\left(\mathrm{Na}_{2} \mathrm{CO}_{3}\right.$ and $\left.\mathrm{CaCO}_{3}\right)$ and furfuryl alcohol (as a binder) allowed to obtain high surface area (up to $333 \mathrm{~m}^{2} / \mathrm{g}$ ) 3D structures. It was discovered and proved experimentally that double layered graphene (DLG) and few layered graphene (FLG) or multi layered graphene (MLG) flakes were basic building stone of the 3D structures. The effectives of the proposed method also consists in the fact that the chemical composition of the 3D materials did not differ dramatically from pristine graphene (Rodriguez-Perez et al. 2013), since only the residues of heteroatoms like oxygen, nitrogen and hydrogen were detected. Thus, the outstanding electric properties of pristine graphene were preserved. The method is suitable for inexpensive manufacturing of graphene-based adsorbents and electrodes for energy storage/generation by electrochemical devices like batteries, capacitors and fuel cells. 3D structured graphene may enable several phenomena based on adsorption process like electrode reactions, heterogeneous catalysis, heavy metal ion adsorption (purification of water) as well as an efficient adsorption of air pollutants like vapors of organic solvents.

Acknowledgements This work was carried out as a result of the research Project No. 2016/23/B/ST5/00658 financed by the National Science Centre (Poland).

Open Access This article is distributed under the terms of the Creative Commons Attribution 4.0 International License (http://creativeco mmons.org/licenses/by/4.0/), which permits unrestricted use, distribution, and reproduction in any medium, provided you give appropriate credit to the original author(s) and the source, provide a link to the Creative Commons license, and indicate if changes were made.

\section{References}

Acik, M., Darling, S.B.: Graphene in perovskite solar cells: device design, characterization and implementation. J. Mater. Chem. A. 4(17), 6185-6235 (2016). https://doi.org/10.1039/C5TA09911K

Cai, X., Lai, L., Shen, Z., Lin, J.: Graphene and graphene-based composites as Li-ion battery electrode materials and their application in full cells. J. Mater. Chem. A. 5(30), 15423-15446 (2017). https ://doi.org/10.1039/C7TA04354F

Cheng, Q., Okamoto, Y., Tamura, N., Tsuji, M., Maruyama, S., Matsuo, Y.: Graphene-Like-Graphite as Fast-Chargeable and HighCapacity Anode Materials for Lithium Ion Batteries. Sci. Rep. 7(1), 14782 (2017). https://doi.org/10.1038/s41598-017-14504-8

Choi, H., Choi, J.S., Kim, J.-S., Choe, J.-H., Chung, K.H., Shin, J.-W., et al.: Flexible and transparent gas molecule sensor integrated with sensing and heating graphene layers. Small 10(18), 3685-3691 (2014)

Cui, X., Zhang, C., Hao, R., Hou, Y.: Liquid-phase exfoliation, functionalization and applications of graphene. Nanoscale 3(5), 2118 $2126(2011)$

Drewniak, S., Pustelny, T., Strupiński, W., Pasternak, I., Opilski, Z.: Metody charakteryzacji grafenu wykorzystywanego w sensorowych układach rezystancyjnych. Prace Naukowe Politechniki Śląskiej. Elektryka(2-3), 63-72 (2014)

Eftekhari, A., Garcia, H.: The necessity of structural irregularities for the chemical applications of graphene. Mater. Today Chem. 4, 1-16 (2017). https://doi.org/10.1016/j.mtchem.2017.02.003

Fan, Z., Zhao, Q., Li, T., Yan, J., Ren, Y., Feng, J., Wei, T.: Easy synthesis of porous graphene nanosheets and their use in supercapacitors. Carbon. 50(4), 1699-1703 (2012). https://doi. org/10.1016/j.carbon.2011.12.016

Gayathri, S., Jayabal, P., Kottaisamy, M., Ramakrishnan, V.: Synthesis of few layer graphene by direct exfoliation of graphite and a Raman spectroscopic study. AIP Adv. 4, 027116 (2014)

Grodecki, K.: Spektroskopia ramanowska grafenu. Mater. Elektron. 41, 1 (2013)

Han, S., Wu, D., Li, S., Zhang, F., Feng, X.: Porous graphene materials for advanced electrochemical energy storage and conversion devices. Adv. Mater. 26(6), 849-864 (2014). https://doi. org/10.1002/adma.201303115 doi

Hancock, Y.: The 2010 nobel prize in physics-ground-breaking experiments on graphene. J. Phys. D: Appl. Phys. 44(47), $473001(2011)$

Hernandez, Y., Nicolosi, V., Lotya, M., Blighe, F.M., Sun, Z., De, S., McGovern, I., Holland, B., Byrne, M., Gun'Ko, Y.K.: Highyield production of graphene by liquid-phase exfoliation of graphite. Nat. Nanotechnol. 3(9), 563 (2008)

Ilnicka, A., Lukaszewicz, J.P.: Synthesis of N-rich microporous carbon materials from chitosan by alkali activation using $\mathrm{Na}_{2} \mathrm{CO}_{3}$. Mater. Sci. Eng. 201, 66-71 (2015)

Ilnicka, A., Lukaszewicz, J.P.: Nanoscale exfoliation of graphene sheets for manufacturing of 3D mesoporous structures. J. Nanosci. Nanotechnol. 16(9), 9997-10000 (2016)

Ilnicka, A., Lukaszewicz, J.: Marine and freshwater feedstocks as a precursor for nitrogen-containing carbons: a review. Mar. Drugs 16(5), 142 (2018)

Ilnicka, A., Kamedulski, P., Beitia, I., Lukaszewicz, J.P.: Threedimensional functionalization of graphene obtained from commercial graphite by liquid phase exfoliation. In: Garbacz, J.K. (ed.) Monograph, vol. XI. Prace Komisji Ekologii i Ochrony Środowiska Bydgoskiego Towarzystwa Naukowego, pp. 127135. Bydgoskie Towarzystwo Naukowe, Bydgoszcz (2017a)

Ilnicka, A., Kamedulski, P., Lukaszewicz, J.P.: Pyrolysis of Chlorella vulgaris as a green chemistry method for manufacturing of nitrogen doped porous carbon materials of high application potential. Mater. Express 7(1), 25-34 (2017b)

Kamedulski, P., Ilnicka, A., Lukaszewicz, J.P.: Advanced graphene exfoliation. In: Garbacz, J.K. (ed.) Monograph, vol. XII. Prace Komisji Ekologii i Ochrony Środowiska Bydgoskiego Towarzystwa Naukowego, pp. 63-72. Bydgowskie Towarzystwo Naukowe, Bydgoszcz (2018a)

Kamedulski, P., Ilnicka, A., Lukaszewicz, J.P.: Selected aspects of graphene exfoliation as an introductory step towards 3D structuring of graphene nano-sheets. Curr. Graphene Sci. 2(2), 106-117 (2018b)

Kamedulski, P., Ilnicka, A., Lukaszewicz, J.P.: The method of producing durable three-dimensional porous matrixes based on graphene flakes obtained by graphite exfoliation. Poland Patent $(2018 \mathrm{c})$

Katsnelson, M.I.: Graphene: carbon in two dimensions. Mater. Today 10(1-2), 20-27 (2007) 
Kim, H., Abdala, A.A., Macosko, C.W.: Graphene/polymer nanocomposites. Macromolecules 43(16), 6515-6530 (2010)

Kucinska, A., Cyganiuk, A., Lukaszewicz, J.P.: A microporous and high surface area active carbon obtained by the heat-treatment of chitosan. Carbon 50(8), 3098-3101 (2012)

Lezanska, M., Olejniczak, A., Pacuła, A., Szymanski, G., Wloch, J.: The influence of microporosity creation in highly mesoporous $\mathrm{N}$-containing carbons obtained from chitosan on their catalytic and electrochemical properties. Catal. Today 227, 223-232 (2014)

Li, C., Zhang, X., Wang, K., Zhang, H., Sun, X., Ma, Y.: Three dimensional graphene networks for supercapacitor electrode materials. New Carbon Mater. 30(3), 193-206 (2015). https://doi. org/10.1016/S1872-5805(15)60185-8

Li, K., Huang, Y., Liu, J., Sarfraz, M., Agboola, P.O., Shakir, I., Xu, Y.: A three-dimensional graphene framework-enabled high-performance stretchable asymmetric supercapacitor. J. Mater. Chem. A. 6(4), 1802-1808 (2018). https://doi.org/10.1039/C7TA09041B

Lim, E.L., Yap, C.C., Jumali, M.H.H., Teridi, M.A.M., Teh, C.H.: A mini review: can graphene be a novel material for perovskite solar cell applications? Nano-Micro Lett. 10(2), 27 (2017). https://doi. org/10.1007/s40820-017-0182-0

Ma, Y., Chen, Y.: Three-dimensional graphene networks: synthesis, properties and applications. Natl. Sci. Rev. 2(1), 40-53 (2015). https://doi.org/10.1093/nsr/nwu072

Mao, S., Lu, G., Chen, J.: Three-dimensional graphene-based composites for energy applications. Nanoscale. 7(16), 6924-6943 (2015). https://doi.org/10.1039/C4NR06609J

Niu, S., Wu, S., Lu, W., Yang, Q., Kang, F.: A one-step hard-templating method for the preparation of a hierarchical microporousmesoporous carbon for lithium-sulfur batteries. New Carbon Mater. 32(4), 289-296 (2017). https://doi.org/10.1016/S1872 -5805(17)60123-9

Novoselov, K.S., Geim, A.K., Morozov, S.V., Jiang, D., Zhang, Y., Dubonos, S.V., Grigorieva, I.V., Firsov, A.A.: Electric field effect in atomically thin carbon films. Science. 306(5696), 666-669 (2004). https://doi.org/10.1126/science.1102896

Pei, S., Cheng, H.-M.: The reduction of graphene oxide. Carbon 50, 3210-3228 (2012)

Ping, Y., Gong, Y., Fu, Q., Pan, C.: Preparation of three-dimensional graphene foam for high performance supercapacitors. Progr. Nat. Sci. 27(2), 177-181 (2017). https://doi.org/10.1016/j. pnsc.2017.03.005

Ravikumar, R., Gopukumar, S.: High quality NMP exfoliated graphene nanosheet-SnO 2 composite anode material for lithium ion battery. Phys. Chem. Chem. Phys. 15(11), 3712-3717 (2013)

Rodriguez-Perez, L., Herranz, M.A., Martin, N.: The chemistry of pristine graphene. Chem. Commun. 49(36), 3721 (2013)

Roy-Mayhew, J.D., Aksay, I.A.: Graphene materials and their use in dye-sensitized solar cells. Chem. Rev. 114(12), 6323-6348 (2014). https://doi.org/10.1021/cr400412a
Smędowski, Ł, Muzyka, R.: Grafen-metody otrzymywania a zastosowanie i właściwości. Karbo 2, 79-87 (2013)

Tian, H., Yang, Y., Xie, D., Cui, Y.-L., Mi, W.-T., Zhang, Y., Ren, T.-L.: Wafer-scale integration of graphene-based electronic, optoelectronic and electroacoustic devices. Sci. Rep. 4, 3598-3598 (2014). https://doi.org/10.1038/srep03598

Torbicz, W., Pijanowska, D.: Zastosowanie grafenu w technice pomiarowej. Przegląd Elektrotechniczny 88(6), 1-7 (2012)

Wang, M., Xu, Y.-X.: Design and construction of three-dimensional graphene/conducting polymer for supercapacitors. Chin. Chem. Lett. 27(8), 1437-1444 (2016). https://doi.org/10.1016/j.cclet .2016.06.048

Yang, C.-R., Tseng, S.-F., Chen, Y.-T.: Characteristics of graphene oxide films reduced by using an atmospheric plasma system. Nanomaterials 8(802), 1-12 (2018)

Yi, M., Shen, Z.: A review on mechanical exfoliation for the scalable production of graphene. J. Mater. Chem. A 3(22), 11700-11715 (2015)

Yu, M., Qiu, W., Wang, F., Zhai, T., Fang, P., Lu, X., Tong, Y.: Three dimensional architectures: design, assembly and application in electrochemical capacitors. J. Mater. Chem. A. 3(31), 1579215823 (2015). https://doi.org/10.1039/C5TA02743H

Yuan, L., Ge, J., Peng, X., Zhang, Q., Wu, Z., Jian, Y., Xiong, X., Yin, H., Han, J.: A reliable way of mechanical exfoliation of large scale two dimensional materials with high quality. AIP Adv. 6(12), 125201 (2016)

Yung, K., Wu, W., Pierpoint, M., Kusmartsev, F.: Introduction to graphene electronics-new era of digital transistors and devices. Contemp. Phys. 54(5), 233-251 (2013)

Zhang, L., Zhang, F., Yang, X., Long, G., Wu, Y., Zhang, T., Leng, K., Huang, Y., Ma, Y., Yu, A., Chen, Y.: Porous 3D graphene-based bulk materials with exceptional high surface area and excellent conductivity for supercapacitors. Sci. Rep. 3, 1408-1408 (2013). https://doi.org/10.1038/srep01408

Zhang, Y., Li, H., Kuo, L., Dong, P., Yan, F.: Recent applications of graphene in dye-sensitized solar cells. Curr. Opin. Colloid Interface Sci. 20(5), 406-415 (2015). https://doi.org/10.1016/j.cocis .2015 .11 .002

Zhong, Y.L., Tian, Z., Simon, G.P., Li, D.: Scalable production of graphene via wet chemistry: progress and challenges. Mater. Today 18(2), 73-78 (2015)

Zhu, Y., Zhang, X., Li, J., Qi, G.: Three-dimensional graphene as gas diffusion layer for micro direct methanol fuel cell. Int. J. Mod. Phys. B. 32(12), 1850145 (2018). https://doi.org/10.1142/s0217 $97921850145 \mathrm{x}$

Publisher's Note Springer Nature remains neutral with regard to jurisdictional claims in published maps and institutional affiliations. 